\title{
Answer to the Letter to the Editor of Dr. Yusuf Izci entitled "Anular closure device: Is it necessary after discectomy?" concerning "The high-risk discectomy patient: prevention of reherniation in patients with large anular defects using an anular closure device" by G. J. Bouma, M. Barth, D. Ledic, M. Vilendecic (2013) Eur Spine J; 22(5):1030-1036
}

\author{
Gerrit J. Bouma \\ Received: 6 August 2013/Revised: 15 September 2013/Accepted: 15 September 2013/Published online: 26 September 2013 \\ (C) Springer-Verlag Berlin Heidelberg 2013
}

Dear Editor,

We appreciate the thoughtful comments by Dr. Izci. Our conclusion that an anular closure device (ACD) may prevent reherniation after limited discectomy was based on our finding of an overall symptomatic reherniation rate of $1.4 \%$ in our patients, which compares favorably to previous studies reporting much higher rates, especially with large anular defects. The relationship between the size of the anular defect and the risk of recurrence has been well documented previously [1]. In addition, the benefits and risks of limited vs. radical discectomy have been investigated in several clinical trials showing less back pain but higher reherniation risk with limited disc removal [2]. It was our assumption that the use of an ACD may overcome the disadvantage of limited discectomy without losing the benefits.

The indication for surgery in our patients was according to generally accepted standards: Persistent radicular pain (VAS $\geq 40$ ) from an MRI-proven lumbar disc herniation that did not respond to conservative treatment for at least 6 weeks. Patients with urgent indications, e.g., progressive paresis or cauda equina syndrome, were not included in our study.

We agree with Dr. Izci that the lack of randomization and a control group represents a weakness of our study, that we also alluded to in our paper. Clearly, a randomized controlled trial (RCT) is warranted and we are happy to report that such a study is currently in progress, with over 400 patients enrolled to date (http://www.clinicaltrials.gov/ ct2/show/NCT01283438).

\section{G. J. Bouma $(\square)$}

Department of Neurosurgery, Academic Medical Center/Sint

Lucas Andreas Ziekenhuis, P.O. Box 9243,

1006 AE Amsterdam, The Netherlands

e-mail: g.j.bouma@amc.uva.nl
The ACD is meant to remain in place permanently and will only be removed in special circumstances. The ACD was removed in one patient in our series with the assistance of a tool provided by the implant manufacturer. Following careful adhesiolysis and mobilization of the dural sac, a small rim of bone posterior to the anchor was removed, where after the device could be extracted without much difficulty.

Previous reports have documented the significant costs associated with recurrent herniation after discectomy [3], and any reduction in rehernation rate that can be achieved may contribute to healthcare savings. But again, the RCT will definitively identify any healthcare savings attributable to the ACD.

In line with Dr. Izci's notion, we also tend to believe that the benefit of an ACD may be greater in patients with large anular defects, but obviously the results of the RCT will have to be awaited to answer this question with more certainty.

Conflict of interest None.

\section{References}

1. Carragee EJ, Han MY, Suen PW, Kim D (2003) Clinical outcomes after lumbar discectomy for sciatica: the effects of fragment type and anular competence. J Bone Joint Surg Am 85-A:102-108

2. Watters WC III, McGirt MJ (2009) An evidence-based review of the literature on the consequences of conservative versus aggressive discectomy for the treatment of primary disc herniation with radiculopathy. Spine J 9:240-257

3. Ambrossi GL, McGirt MJ, Sciubba DM, Witham TF, Wolinsky JP, Gokaslan ZL, Long DM (2009) Recurrent lumbar disc herniation after single-level lumbar discectomy: incidence and health care cost analysis. Neurosurgery 65:574-578 